\title{
CURRÍCULO DA FORMAÇÃO DE PROFESSSORES NAS CIÊNCIAS BIOLÓGICAS: POR UMA ABORDAGEM DISCURSIVA PARA INVESTIGAR A RELAÇÃO ENTRE TEORIA E PRÁTICA
}

\author{
BIOLOGICAL SCIENCES TEACHER TRAINING CURRICULUM: FOR A DISCURSIVE \\ APPROACH TO INVESTIGATE THE RELATION BETWEEN THEORY AND PRACTICE \\ PLAN DE FORMACIÓN DE PROFESSORES EN CIENCIAS BIOLÓGICAS: HACIA UN \\ ENFOQUE DISCURSIVO PARA INVESTIGAR LA RELACIÓN TEORÍA Y PRÁCTICA
}

\author{
Marcia Serra Ferreira ${ }^{1}$ \\ André Vitor Fernandes dos Santos ${ }^{2}$ \\ Leticia Terreri ${ }^{3}$
}

\begin{abstract}
RESUMO
$\mathrm{O}$ artigo apresenta o modo como vimos produzindo uma abordagem discursiva para investigar a história de diferentes currículos e disciplinas acadêmicas, em meio às políticas voltadas para a formação de professores, com especial interesse na relação entre teoria e prática em cursos na área das Ciências Biológicas. Buscando compreender a produção das políticas como uma possibilidade de construção de uma história do (e no) tempo presente, investimos no diálogo com Michel Foucault e alguns de seus interlocutores no campo do Currículo. Aproximando-nos de Thomas Popkewitz, consideramos que a distinção entre teoria e prática é parte dos dispositivos que constroem os próprios professores, constituindo um par binário no qual a significação do primeiro termo alimenta o sentido do segundo e vice-versa, criando regras para a formação de professores. As reformas curriculares situam-se, então, em meio a um sistema de raciocínio no qual a distinção entre teoria e prática é parte da estrutura que fixa papéis e produz efeitos de verdade. No que refere às Ciências Biológicas, tais sentidos têm sido elaborados em meio a discursos que aproximam e, simultaneamente, afastam as práticas científica e docente, criando carga horária prática a partir de temáticas e metodologias advindas da ciência de referência ou, então, da cultura da escola. Nesse movimento, 'antigos' e 'novos' componentes curriculares produzem e legitimam noções de conhecimento, pesquisa, ensino e extensão que significam a teoria e a prática conjuntamente, em um sistema de relações por meio do qual nos definimos como bons ou maus professores de Ciências e Biologia.
\end{abstract}

PALAVRAS-CHAVE: Currículo. Relação teoria-prática. Formação de professores. Ciências Biológicas. Políticas públicas em educação.

ABSTRACT

This article presents the way we are producing a discursive approach to investigate the history of different curricula and academic disciplines amid the policies for teacher training, with special interest in the relation

\footnotetext{
${ }^{1}$ Doutora em Educação pela Universidade Federal do Rio de Janeiro, UFRJ, Rio de Janeiro, RJ - Brasil. Professora do Departamento de Educação da Universidade Federal do Rio de Janeiro, UFRJ, Rio de Janeiro, RJ - Brasil. Bolsista de Produtividade (PQ2/CNPq) e Jovem Cientista do Nosso Estado (JCNE/FAPERJ). E-mail: marciaserra.f@gmail.com.

${ }^{2}$ Mestre em Educação pela Universidade Federal do Rio de Janeiro, UFRJ, Rio de Janeiro, RJ - Brasil. Doutorando do Programa de Pós-Graduação em Educação pela mesma universidade. Foi Visiting Scholar na University of Wisconsin-Madison, Estados Unidos, com bolsa Capes - Proc. no. BEX 3599/15-9. PesquisadorTecnologista em Informações e Avaliações Educacionais no Instituto Nacional de Estudos e Pesquisas Educacionais Anísio Teixeira, INEP, Brasília, DF - Brasil. E-mail: andrevfsantos@ gmail.com.

${ }^{3}$ Mestra em Educação pela Universidade Federal do Rio de Janeiro, UFRJ, Rio de Janeiro, RJ - Brasil. Doutoranda do Programa de Pós-Graduação em Educação pela mesma universidade. Foi bolsista Capes e FAPERJ. Pesquisadora-Tecnologista em Informações e Avaliações Educacionais no Instituto Nacional de Estudos e Pesquisas Educacionais Anísio Teixeira, INEP, Brasília, DF - Brasil.

E-mail: leterreri@gmail.com.
}

Recebido em: 10/03/2016 - Aprovado em: 16/05/2016

\begin{tabular}{l|l|l|l|l|l|l|} 
(C) ETD-Educ. temat. digit. & Campinas, SP & v.18 & n. 2 & p.495-510 & abr./jun.2016 & ISSN 1676-2592
\end{tabular}


between theory and practice in courses in the area of Biology. In order to understand the production of policies as a possibility to build a history in and of the present, we connected with Michel Foucault and some of his interlocutors in the Curriculum field. In dialogue with Thomas Popkewitz's production, we consider that the distinction between theory and practice is part of the dispositifs that build specific kinds of teachers, forming a binary pair in which the meaning of the first term feeds the meaning of the second and vice versa, creating rules for teacher training. Curricular reforms are situated then in the midst of a reasoning system in which the distinction between theory and practice is part of the structure that fix roles and produce effects of truth. Regarding Biology, such meanings have been developed amid discourses that brings together, and simultaneously, puts away scientific and teaching practices, creating practical study load from themes and methodologies that come from reference sciences or so, from school culture. In this movement, 'old' and 'new' curriculum components produce and legitimize notions of knowledge, research, education and extension that mean the theory and practice together in a system of relations which we define ourselves as good or bad Science and Biology teachers.

KEYWORDS: Curriculum. Theory-practice relation. Teacher education. Biology. Educational policy.

\section{RESUMEN}

El artículo muestra como hemos producido un enfoque discursivo para investigar la historia de diferentes planes de estudio y disciplinas académicas, por medio de las políticas de formación inicial, con especial interés en la relación entre la teoría y la práctica en cursos en el área de Ciencias Biológicas. Tratar de entender la producción de políticas como una posibilidad para construir una historia en (y en el) tiempo presente, hemos invertido en el diálogo con Michel Foucault y algunos de sus interlocutores en el campo de Curriculum. Acercarse a Thomas Popkewitz, consideramos que la distinción entre la teoría y la práctica es parte de los dispositivos que se basan los propios docentes, la formación de un par binario en el que el significado del primer término alimenta el sentido de el segundo y viceversa, creando reglas para la formación del profesorado. Las reformas curriculares se sitúan en medio de un sistema de razonamiento en el que la distinción entre la teoría y la práctica es parte de la estructura que fija las funciones y producen efectos de verdad. En cuanto a las Ciencias Biológicas tales sentidos se han desarrollado en medio de discursos que se acercan y al mismo tiempo lejos de las prácticas científicas y docentes, la creación de horas prácticas de temáticas y metodologías que resultan de la ciencia de referencia más o menos, la cultura de la escuela. En este movimiento, "viejo" y "nuevo" componentes del plan de estudios producen y legitiman las nociones de conocimiento, la investigación, la educación y la extensión que significa la teoría y la práctica juntos en un sistema de relaciones en la que nos definimos como el bueno o el malo maestro de la Ciencia y la Biología.

PALABRAS CLAVE: Plan de estudios. Relación entre la teoría y la práctica. Formación del profesorado. Ciencias Biológicas. Políticas públicas en educación.

\section{INICIANDO A CONVERSA: DELINEANDO OS OBJETIVOS DA INVESTIGAÇÃO}

No presente trabalho, temos como objetivo apresentar o modo como vimos produzindo, no Grupo de Estudos em História do Currículo, uma abordagem discursiva para investigar a história de diferentes currículos e disciplinas acadêmicas, em meio às políticas voltadas para a formação de professores, com especial interesse nas Ciências Biológicas. ${ }^{i}$ Ele se insere em meio aos estudos que vimos desenvolvendo no âmbito do Núcleo de Estudos de Currículo da Faculdade de Educação da Universidade Federal do Rio de Janeiro (NEC/UFRJ), "buscando compreender como, em diferentes campos do conhecimento, têm sido travadas inúmeras disputas por validar e hegemonizar determinados conhecimentos em detrimento de outros, produzindo verdades sobre o ensino e a formação de professores" (FERREIRA, 2015, p. 265-266, grifo original).

Interessa-nos, em especial, focalizar a relação entre teoria e prática em uma formação de professores específica - a que se desenvolve nas Ciências Biológicas - como um par

\begin{tabular}{|c|c|c|c|c|c|c|} 
(C) ETD - Educ. temat. digit. & Campinas, SP & v.18 & n. 2 & p.495-510 & abr./jun.2016 & ISSN 1676-2592
\end{tabular}


binário (tal como proposto por POPKEWITZ, 2001) no qual os termos se constituem mutuamente, ao invés de tratá-los como 'opostos' e/ou 'contraditórios'. Afinal, ao analisar diferentes binários produzidos nos discursos dos professores em um programa voltado para a formação de quadros para a atuação com estudantes de escolas urbanas e rurais nos Estados Unidos - o 'Teach for America' -, Thomas Popkewitz (2001) percebe, nas extremidades desses binários, o posicionamento de enunciados distintos: um deles significando padrões identificados com uma razão universal, que são traduzidos por normas de inteligência e de competência dos estudantes; o outro pela oposição a essa razão. Para o autor:

\begin{abstract}
Entretanto, a estrutura dos binários não parece constituída de separações, mas de um contínuo de valores em que um lado das distinções é privilegiado, à medida que o conjunto 'cria' o que é 'bom' e normal. A construção dos binários é obscurecida à medida que é considerada a aplicação dos valores universais quando se pensa sobre alcances e padrões de desenvolvimento de todas as crianças. [...] esses valores universais, supostamente os mesmos para todas as crianças, são ficções, as quais estão incorporadas nas práticas pedagógicas que 'criam' as diferenças e a diversidade a partir das normas universais de igualdade (POPKEWITZ, 2001, p. 48, grifos originais).
\end{abstract}

Inspirados nesse debate, percebemos os enunciados que vêm historicamente relacionando teoria e prática na formação de professores no Brasil também posicionados nos polos de um par binário produtor de modelos formativos que, em um dos extremos, produziu o modelo $3+1$ e, no outro extremo, tem investido em uma racionalidade que dá centralidade à dimensão prática. Tais racionalidades, do mesmo modo que os discursos docentes investigados por Popkewitz (2001), produzem um contínuo que vem constituindo a formação de professores no país em meio a um tensionamento do par binário teoria/prática.

Nossa opção por investigar a relação entre teoria e prática "toma como referência o fato de que esse binômio tem se constituído como uma questão central para a formação de professores secundários no Brasil desde a sua inauguração no ensino superior, nos anos de 1930, em um modelo que ficou conhecido como '3+1'” (FERREIRA, 2015, p. 276, grifo original). Nesse contexto, no qual a Licenciatura era entendida como uma formação complementar ao Bacharelado, foram sendo produzidos significados particulares sobre a referida relação, em um movimento que veio reforçando uma supervalorização dos "conhecimentos científicos, em detrimento da técnica - aqui entendida como ciência aplicada -, que, por sua vez, subordina a prática compreendida como aplicação dessa técnica" (ANDRADE et al., 2004, p. 11). Ainda que percebamos uma série de críticas e de iniciativas que caminham no sentido de subverter esse modo de significar a relação entre teoria e prática, tal perspectiva convive e se hibridiza, no sentido proposto por Garcia Canclini ii (2000), a uma série de novas propostas no tempo presente. É o caso, por exemplo, de documentos oficiais como os Pareceres CNE/CP 9/2001 iii e 28/2001 iv e as Resoluções CNE/CP 1/2002 e $2 / 2002^{\text {vi }}$, que legislaram sobre a formação de professores no Brasil até o ano de 2015. Neles, de acordo com Terreri \& Ferreira (2013, p. 1002), o modelo 3+1 'deveria' ser superado por um novo paradigma, pautado nos seguintes aspectos: "uma articulação entre teoria e prática no processo formativo; uma formação baseada em um currículo por competências; uma efetiva aproximação entre as instituições formadoras e os sistemas públicos de ensino". Mais recentemente, com a promulgação da Resolução $\mathrm{CNE} / \mathrm{CP} 2 / 2015^{\text {vii }}$, que redefiniu as \begin{tabular}{l|l|l|l|l|l|l|} 
(C) ETD - Educ. temat. digit. & Campinas, SP & v.18 & n. 2 & p.495-510 & abr./jun.2016 & ISSN 1676-2592
\end{tabular} 
diretrizes curriculares para a formação de professores em nível superior no país, a centralidade da dimensão prática não somente é reafirmada como é reconhecido o caráter contínuo do par binário teoria/prática.

Buscando compreender a produção das políticas como uma instigante possibilidade de construção de uma história do (e no) tempo presente e, dessa forma, investigar a História e as Políticas de Currículo, em especial aquelas voltadas para a formação de professores nas Ciências Biológicas, apostamos em uma abordagem discursiva, no diálogo com determinadas noções sobre discurso desenvolvidas por Michel Foucault (2003 e 2012). Além disso, buscamos ampliar a utilização dessas noções por meio de uma aproximação com alguns de seus interlocutores no campo do Currículo, tais como Rosa Maria Fischer (2003 e 2012), Thomas Popkewitz (1994, 1997 e 2001) e Alfredo Veiga-Neto (2009 e 2012). Nesses diálogos, temos investido em um duplo deslocamento: um primeiro, que focaliza a forma pela qual temos ressignificado noções tradicionalmente utilizadas nos estudos sócio-históricos e de políticas, tais como as de comunidade disciplinar (GOODSON, 1997) e epistêmica (DIAS \& LÓPEZ, 2006), e as de estabilidade e mudança curricular (GOODSON, 1997); um segundo, do qual também decorre o primeiro, em que temos problematizado o nosso próprio fazer pesquisa, produzindo outras formas de pensar o conhecimento, a história e a política. Nesse movimento, assumimos o que Veiga-Neto (2012, p. 274-275) define como uma postura de vigilância epistemológica e de hipercrítica, desconfiando de fundamentos anteriores e colocando "sempre à prova a coerência, a pertinência e a racionalidade do que é pensado e dito, seja em suas relações com o que se estabeleceu como fundamentos ou pontos de partida, seja da lógica interna do pensado e do dito".

Isso não significa a assunção de uma espécie de 'vale tudo' na produção do conhecimento científico, mas entender que o que chamamos de 'realidade' não é definido fora dos jogos de linguagem e dos sistemas de classificação que produzem os fatos como fenômenos discursivos (HALL, 1997). Percebemos a fecundidade de tal abordagem "para problematizar análises que ora investem em sujeitos centrados, autônomos e conscientes, ora enfatizam o determinismo de estruturas sociais mais amplas" (FERREIRA, 2013, p. 82), destacando a produtividade do poder na constituição dos currículos e das disciplinas, assim como das subjetividades docentes e discentes. É nesse âmbito que realizamos um conjunto de pesquisas que têm se dedicado a investigar a formação inicial de professores nas Ciências Biológicas, situadas sócio-historicamente em diferentes instituições, percebendo como as mesmas elaboram e ressignificam as políticas de currículo no contexto da prática (BOWE, BALL \& GOLD, 1992), em espaços/tempos curriculares como a Prática de Ensino (TERRERI, 2008; TERRERI \& FERREIRA, 2013) e, especialmente, a Prática como Componente Curricular (VIANA et al., 2012, 2013 e 2015; FERREIRA, SOUSA \& CASARIEGO, 2013; SOUZA et al., 2015). 


\title{
2 PRODUZINDO UMA ABORDAGEM DISCURSIVA: DIÁLOGOS COM FOUCAULT
}

Como já apontado, temos investido na elaboração de uma abordagem discursiva para a História e as Políticas de Currículo que assume a 'virada linguística' (POPKEWITZ, 1994) e, nesse movimento, recusa uma perspectiva representacional da realidade. Em outras palavras, temos apostado em uma perspectiva que rompe com a noção de que os textos carregariam consigo sentidos que representariam a priori os objetos sobre os quais falam. Assumir tal ruptura significa investir na produção de uma forma de pensar que nos permita perceber os padrões de pensamento e os sistemas de raciocínio como mecanismos que constroem nossas próprias visões sobre determinados objetos, significando-os de determinadas formas e nos oferecendo grades de inteligibilidade bastante particulares para classificá-los e ordená-los (POPKEWITZ, 1994).

Investigando as políticas públicas para a formação de professores que tem sido produzidas no tempo presente - no caso deste estudo, a partir dos anos 2000 -, assumimos uma noção de história que, de acordo com Gabriel (2012, p. 203, grifos originais), reconhece a "necessidade de 'partir do presente' ao invés de 'correr atrás dele' como ponto de chegada". No diálogo com a hermenêutica de Ricoeurviii, essa autora destaca as contribuições do historiador para pensar "a capacidade que a História, como um 'singular coletivo', tem de dar uma resposta satisfatória à aporia da fragmentação passado, presente e futuro" (GABRIEL, 2012, p. 195, grifo original), tomando o presente como referência para significar, de modo articulado, passado e futuro. Ampliando esse diálogo para pensarmos a escrita de uma história do (e no) tempo presente, nos aproximamos de Popkewitz (2008) ao abordar a relação entre teoria e prática como um conjunto de teses culturais que não são 'invenções' propriamente do nosso tempo, mas que circulam no âmbito da formação de professores no país desde, pelo menos, a década de 1930. Para o autor:

\begin{abstract}
A História é a busca por localizar a emergência do sujeito como um sistema do qual governa o que é possível de dizer, pensar e fazer. A problematização do que é tomado como natural e fora do "tempo" torna frágil a relação de causalidade entre o presente e as possibilidades de alternativas que estão fora das inscrições existentes de um passado que governam o futuro. Sua estratégia para pensar sobre a mudança é diferente daquelas incorporadas no historicismo . A agência está em privar o self da estabilidade tranquilizadora da vida e em desafiar a suposição de que a liberdade e a libertação são dependentes do cálculo e da gestão do sujeito humano. Onde paradoxalmente o historicismo organiza o passado para falar sobre o futuro, historicizar é um projeto fundamental para tornar frágil a aparente causalidade do presente (POPKEWITZ, 2014, p. 12, tradução livre). ${ }^{\text {ix }}$
\end{abstract}

Tomando como referência essa noção de história na qual o presente articula passado e futuro (GABRIEL, 2012), entendemos os currículos da formação de professores sendo discursivamente produzidos, no tempo presente, em meio à elaboração de políticas em diferentes contextos como, por exemplo: o contexto de influência, o contexto de produção dos textos e o contexto da prática (BOWE, BALL \& GOLD, 1992). Como todo modelo, o ciclo contínuo produtor de políticas (BOWE, BALL \& GOLD, 1992) é uma abstração que nos ajuda na compreensão de como se dão os processos de elaboração e ressignificação das 
políticas educacionais. Para Bowe, Ball \& Gold (1992), o primeiro desses contextos - isto é, o contexto de influência - seria o lócus em que a política pública é normalmente iniciada e onde os discursos das políticas começariam a ser formulados ${ }^{\mathrm{x}}$. Nele ocorreriam as disputas em torno da significação dos propósitos sociais da educação e do que significa ser educado. Aí atuariam os partidos políticos, os processos legislativos, os governos nacionais e os Estados com os quais se mantém relações, e também as agências multilaterais. Os autores defendem que seria no contexto de influência que os conceitos-chave das políticas são estabelecidos, adquirindo legitimidade para prover o discurso e o léxico necessários à iniciação das mesmas. Já no contexto de produção dos textos figuraria o poder central e, como o próprio nome sugere, é nele em que os textos das políticas seriam elaborados e articulados com a linguagem do interesse público em geral (BOWE, BALL \& GOLD, 1992). Por fim, de acordo com o modelo proposto por Bowe, Ball \& Gold (1992), o contexto da prática seria aquele para o qual as políticas são endereçadas, sendo ressignificadas localmente em espaços como, por exemplo, escolas e universidades.

O ponto central desse modelo poderia estar resumido em dois aspectos: o primeiro deles é que haveria entre esses três contextos uma circulação dos discursos produzidos em cada um deles, o que caracterizaria um ciclo contínuo de políticas; o segundo aspecto é que esses discursos, ao circularem pelos diversos contextos, estariam sujeitos a 'novas' interpretações e a 'recriações' (BOWE, BALL \& GOLD, 1992). A partir da intensificação de nossos diálogos com as produções de Michel Foucault (2003 e 2012), temos, em certa medida, ressignificado a forma como compreendemos e empregamos essa noção de um ciclo contínuo produtor de políticas, radicalizando ainda mais a noção de obliquidade do poder e do papel da circulação dos discursos e, portanto, da ocupação das múltiplas posições de sujeito nos processos de produção das políticas. Em diálogo com esse modelo, entendemos que, no que se refere à formação inicial de professores em nosso país, as teses culturais sobre a relação entre teoria e prática vêm sendo historicamente ressignificadas em um ciclo contínuo de produção de políticas, no qual variados enunciados se articulam e se hibridizam, em meio à relações assimétricas de poder (BOWE, BALL \& GOLD, 1992). Temos nos inclinado a pensar que a centralidade da relação entre teoria e prática nas políticas educacionais é resultado da circulação, no contexto de influência, de discursos que foram elaborados no âmbito da formação de professores, ou seja, no contexto da prática.

O que propomos, então, é a produção de uma abordagem discursiva para investigar a História do Currículo e das Disciplinas, no tempo presente, como parte de um ciclo contínuo produtor de políticas, com um especial interesse no contexto da prática. Nesse movimento, consideramos a escrita da história como uma atividade que nos leva, no presente, a desenhar certas molduras que nos possibilitam enxergar um determinado conjunto de acontecimentos do passado. Vimos entendendo, assim, que "a história, em seus significados modernos, envolve procedimentos que constroem seu objeto através de lentes conceituais" (POPKEWITZ, 1994, p. 175), elaborando uma interpretação que é produtora do próprio passado. Ela é, portanto, discurso, ou seja, um "conjunto de enunciados que se apoia em um mesmo sistema de formação" (FOUCAULT, 2012, p. 131). Operando com tal noção, temos defendido que a perspectiva por nós adotada: 
Não abandona a meta de produzir séries que vem informando os estudos históricos. Afinal, ainda que estes tenham problematizado a constituição de relações causais e/ou deterministas, a História permanece interessada na descrição de distintos tipos de acontecimentos em séries definidas que se sucedem, se sobrepõem e, simultaneamente, se entrecruzam (FOUCAULT, 2010) ${ }^{\mathrm{xi}}$. (FERREIRA, 2013, p. 82-83)

Nosso interesse pela elaboração de séries históricas não parte, portanto, da adoção de regras previamente definidas com vistas a procurar a 'origem' e/ou a 'verdade' das coisas; tampouco pretende encaixar os discursos investigados em classificações já produzidas. Diferentemente, temos investido na construção de um modo de fazer História do Currículo e das Disciplinas que pretende realizar "uma 'descrição dos acontecimentos discursivos' como horizonte para a busca das unidades que aí se formam” (FOUCAULT, 2012, p. 32-33, grifos originais), focalizando as relações que são produtoras de regularidades. Afinal, para Foucault (2012), o discurso pode ser entendido como um sistema de relações que compõem formações discursivas, as quais abrangem um sistema de dispersão que possui certa regularidade. A regularidade discursiva é, então, o que agrega enunciados dispersos, criando as séries e uma unidade dentro de uma determinada formação discursiva. Conforme apontado por Ferreira (2013, p. 82-83):

Essa noção de discurso também se afirma em meio a uma visão de descontinuidade que, para Foucault (2010, p. 10), deixa de ser uma característica dos acontecimentos a ser combatida, "o negativo da leitura histórica", para se tornar "o elemento positivo que determina seu objeto e valida a sua análise". Afinal, "de onde poderia ele [o historiador] falar, na verdade, senão a partir dessa ruptura que lhe oferece como objeto a história - e sua própria história?" (FOUCAULT, 2010, p. 10).

Nessa perspectiva, interessa-nos, portanto, as regras que produzem regularidades discursivas, em meio à elaboração de séries descontínuas que significam as coisas do mundo. Tais regras regulam o que Foucault (2012, p. 144) caracteriza como prática discursiva: "um conjunto de regras anônimas, históricas, sempre determinadas no tempo e no espaço, que definiram, em uma dada época e para uma determinada área social, econômica e geográfica ou linguística, as condições de exercício da função enunciativa".

É na dimensão do que Foucault (2003) chama de 'filosofia do acontecimento' que nos propomos a pensar e problematizar o discurso. Nesse sentido, interpretamos as políticas curriculares historicamente produzidas para a formação de professores em Ciências Biológicas como acontecimentos discursivos, considerando o material empírico que temos organizado documentos oficiais produzidos nos diferentes contextos produtores de políticas, materiais curriculares utilizados nos cursos, livros acadêmicos e transcrições de entrevistas com formadores de professores - como uma população de acontecimentos no espaço do discurso em geral. Tal abordagem, de acordo com Foucault (2012, p. 33), "se distingue facilmente da análise da língua". Afinal, ainda que só possamos:

Estabelecer um sistema linguístico (se não o construímos artificialmente) utilizando um corpo de enunciados ou uma coleção de fatos de discurso; [...] trata-se, então, de definir, a partir desse conjunto que tem valor de amostra, regras que permitam construir eventualmente outros enunciados diferentes daqueles (FOUCAULT, 2012, p. 33). 
Como já explicitado, Foucault (2003 e 2012) pontua a necessidade de considerarmos os acontecimentos discursivos como séries descontínuas, que não se referem à sucessão dos instantes do tempo ou à pluralidade dos diversos sujeitos pensantes; para ele, "trata-se de cesuras que rompem o instante e dispersam o sujeito em uma pluralidade de posições e de funções possíveis" (FOUCAULT, 2003, p. 58). Nesse movimento, o autor busca romper com a filosofia do sujeito, contestando o sujeito transcendental, na intenção de descentrá-lo e de pensar outras subjetividades possíveis. De acordo com Fischer (2012, p. 82, grifo original), dialogar com essa noção implica que, ao analisar o discurso, "não estamos diante da manifestação de 'um' sujeito", mas, de modo distinto, "nos defrontamos com o lugar de sua dispersão e de sua descontinuidade, já que o sujeito da linguagem não é um sujeito em si, idealizado, essencial, origem inarredável do sentido: ele é ao mesmo tempo falante e falado, porque através dele outros ditos se dizem". Entendemos que pensar o descentramento do sujeito em uma abordagem discursiva para investigar, sócio-historicamente, a relação entre teoria e prática nos currículos da formação de professores é, antes de tudo, problematizar a própria forma como vimos pensando o lugar social desses profissionais e as identidades que vimos projetando para eles. Afinal, que regras tem definido a formação de professores 'críticos' e 'reflexivos'? Como vamos nos constituindo como professores - e como formadores de professores - de Ciências e Biologia regulados por enunciados que dizem o que somos e o que não 'devemos' ser, ocupando posições de sujeito em torno das quais definimos os currículos e somos definidos por eles?

Ao problematizar o sujeito dos enunciados, Foucault (2012) propõe entendê-lo como uma função, como um lugar determinado e vazio que pode ser ocupado por indivíduos diferentes. Esse lugar é variável e condição de existência dos enunciados. Deste modo, "descrever uma formulação enquanto enunciado não consiste em analisar as relações entre autor e o que ele disse (ou quis dizer, ou disse sem querer), mas em determinar qual é a posição que pode e deve ocupar todo indivíduo para ser seu sujeito" (FOUCAULT, 2012, p. 116). Os discursos não são, portanto, a manifestação de um sujeito da razão, mas sim "um conjunto em que podem ser determinadas a dispersão do sujeito e sua descontinuidade em relação a si mesmo" (FOUCAULT, 2012, p. 66). Em diálogo com essa perspectiva, nos interessa menos entender a atuação de um (ou de uns) sujeito(s)-indivíduo(s) no processo de produção dos currículos, e mais analisar as posições de sujeito que podem ser ocupadas por alguns indivíduos e não outros, de onde se pode dizer algumas coisas e não outras, em situações provisórias e contingenciais que caracterizam o jogo político de significação da formação de professores em Ciências Biológicas. Afinal, segundo Foucault (2003, p. 37):

\footnotetext{
Ninguém entrará na ordem do discurso se não satisfizer a certas exigências ou se não for, de início, qualificado para fazê-lo. Mais precisamente: nem todas as regiões do discurso são igualmente abertas e penetráveis; algumas são altamente proibidas (diferenciadas e diferenciantes), enquanto outras parecem quase abertas a todos os ventos e postas, sem restrição prévia, à disposição de cada sujeito que fala.
}

Nessa perspectiva, tem nos parecido potente a opção por focalizar a produção discursiva sobre e na formação docente como uma atividade que faz irromper, em determinados momentos históricos, tipos particulares de enunciações que, simultaneamente, regulam e são reguladas pelo que pode ser dito sobre a formação de professores no país. 


\section{INVESTIGANDO A RELAÇÃO TEORIA-PRÁTICA: UM EXERCÍCIO DE ANÁLISE}

Assumindo que os discursos sobre a teoria e a prática vêm sendo historicamente elaborados em um sistema de relações que produz a formação de professores no país, temos investido em uma análise que pretende refletir acerca da dicotomia entre tais significantes como uma aporia e pensar, no diálogo com a noção de discurso desenvolvida por Michel Foucault, que:

O ponto importante da análise é que as regras que caracterizam um discurso como individualidade se apresentam sempre como um sistema de relações. São as relações entre objetos, entre tipos enunciativos, entre conceitos e entre estratégias que possibilitam a passagem da dispersão à regularidade (MACHADO, 2009, p. 149).

Isso significa operar em uma perspectiva que se desloca das análises usualmente produzidas na área, nas quais as políticas dos anos 2000 têm sido percebidas como distanciadas dos conhecimentos teóricos de referência e fortemente ancoradas na prática (ver, por exemplo, ANDRADE et al., 2004; AYRES, 2006). Diferentemente, nossa opção por focalizar a relação (e não a oposição) entre teoria e prática pauta-se em um olhar teórico que busca compreender as condições históricas de irrupção desses conceitos, produzindo outros ditos sobre eles que os colocam em um sistema. Afinal, para Foucault (2012, p. 35), os acontecimentos discursivos não devem ser descritos com a simples finalidade de "disseminar uma poeira de fatos"; eles também não devem ser percebidos em meio à organizações preexistentes que viriam à tona na investigação. A ideia é analisá-los em um jogo de relações nos quais se busca estabelecer a regularidade dos enunciados, no sentido de entender as condições de existência dos mesmos, como aparecem e como se distribuem no interior de um conjunto, com vistas a encontrar as "regras de formação" dos discursos (MACHADO, 2009, p. 146).

Nesse movimento, ao invés de recusar o diálogo com noções de teoria e prática que as colocam, historicamente, em posições excludentes, contraditórias e/ou dicotômicas, assumimos que as mesmas vêm produzindo um sistema de raciocínio para pensar a formação de professores. No diálogo com Popkewitz (2001), consideramos que essa distinção entre teoria e prática é parte dos dispositivos que constroem os próprios professores, em um processo no qual os inserimos em uma ordem discursiva que, em meio à relações de poder, fixa papéis e produz efeitos de verdade. A noção de como os discursos 'fabricam' determinados tipos de pessoas pode ser encontrada, também, nas produções de Ian Hacking (2007). Para o autor, esse processo operaria de duas formas: a primeira forma seria o que ele chama de 'making up people' e se relaciona com a maneira pela qual as classificações científicas trazem à tona modos de ser específicos; a segunda forma estaria relacionada a um 'looping effect', que se refere à interação dos indivíduos classificados com a própria classificação. Como o autor expõe: 
Às vezes nós estudamos um tipo de pessoa apenas para admirar, compreender, incentivar e talvez até mesmo para imitar, como (por vezes) com o gênio. Concebemos esses tipos de pessoas como dados, como classes definidas por propriedades definitivas. Quanto mais conhecermos sobre essas propriedades, mais seremos capazes de controlar, ajudar, mudar, ou imitá-las melhor. Mas não é bem assim. Elas são alvos móveis, porque nossas investigações interagem com os próprios alvos e os modifica. E já que eles são modificados, eles não são exatamente o mesmo tipo de pessoas como antes. $\mathrm{O}$ alvo foi movido. Esse é o looping effect. Às vezes, nossas ciências criam tipos de pessoas que, em certo sentido, não existiam antes. Isso é making people up (HACKING, 2007, p. 293). ${ }^{\text {xii }}$

Embora Hacking (2007) esteja focalizando, especificamente, como determinados tipos de sujeitos são produzidos nas e pelas pesquisas, ele nos ajuda a pensar como as políticas educacionais produzem certos tipos de sujeitos docentes e discentes. Percebemos, nesse diálogo, os significantes teoria e prática como constituintes de um par binário ao qual se associam variados outros binômios que significam os currículos da formação de professores - tais como velhos ou novos, ultrapassados ou contemporâneos, distantes ou próximos da realidade -, regulando o próprio ofício docente. É em meio a esse sistema que nos definimos como 'bons' ou 'maus' professores de Ciências e Biologia, tomando decisões sobre 'o que' e 'como' ensinar em meio a discursos que nos constituem e nos posicionam no mundo.

Assim, ainda que a prática esteja assumindo, no tempo presente, uma posição de destaque nos discursos que produzem as políticas para a formação de professores no país, ela não se refere apenas ao que é prático nos currículos, uma vez que se constrói em meio a um par binário no qual teoria e prática formam um sistema de relações. Nele, a significação do primeiro termo alimenta o sentido do segundo e vice-versa, em um movimento que produz a regularidade do discurso, isto é, cria regras para a formação de professores e, no caso desse estudo, para essa formação inicial no âmbito das Ciências Biológicas. Aqui, assim como na investigação realizada por Popkewitz (2001, p. 88, grifo original) e já mencionada, sobre o programa estadunidense 'Teach for America', “a prática não é externa à teoria, é sim um conceito teórico que 'conta' a alguém como o mundo deve ser agregado e pensado". Em tal perspectiva, o autor destaca o quanto aquilo que relacionamos aos saberes e experiências práticas fixam limites para o que é 'adequado' e 'bom' (assim como para o que é ‘inadequado' e 'ruim') no ofício docente.

Podemos dizer, então, que as reformas curriculares que vieram ocorrendo na formação inicial de professores, no contexto de produção de textos oficiais como os Pareceres CNE/CP 9/2001 $1^{\text {xiii }}, 28 / 2001^{\text {xiv }}$ e $2 / 2015^{\mathrm{xv}}$ e as Resoluções CNE/CP $1 / 2002^{\text {xvi }}, 2 / 2002^{\text {xvii }}$ e $2 / 2015^{\text {xviii }}$ situam-se em um sistema de raciocínio no qual, ainda que a prática seja arduamente defendida, os significados que assume são produzidos no diálogo com a teoria. Nesse contexto, em um movimento ambivalente, percebemos a dimensão prática sendo defendida como um princípio organizador de todo o currículo da referida formação e, simultaneamente, como um aspecto que deve ser ensinado em componentes específicos, tais como o 'Estágio Curricular Supervisionado' e aquilo que tem sido visto como uma 'novidade': a 'Prática como Componente Curricular' (TERRERI \& FERREIRA, 2013). Também aqui, do mesmo modo que na relação entre teoria e prática, a novidade tem sido significada em um par binário 
no qual a tradição é o ‘outro’ dessa relação.

Partindo dessas reflexões, temos produzido uma análise na qual destacamos que, na formação inicial de professores nas Ciências Biológicas, os sentidos das relações entre teoria e prática têm sido elaborados em meio à construção de discursos que aproximam a prática científica da prática docente, criando carga horária prática a partir de temáticas e de metodologias advindas da ciência de referência, e, simultaneamente, as afastam, entendendo que as especificidades da prática docente referem-se menos à ciência e mais à cultura da escola (FERREIRA, SOUSA \& CASARIEGO, 2013). Nesse movimento, 'antigos' e 'novos' componentes curriculares produzem e legitimam noções de conhecimento, de pesquisa, de ensino e de extensão que significam ambos os termos - teoria e prática - conjuntamente, em um sistema de relações no qual:

\begin{abstract}
Os dois elementos incompatíveis são formados da mesma maneira e a partir das mesmas regras; suas condições de aparecimento são idênticas; situam-se em um mesmo nível; e em vez de constituírem uma pura e simples falta de coerência formam uma alternativa: mesmo que segundo a cronologia não apareçam ao mesmo tempo, que não tenham tido a mesma importância, e que não tenham sido representados, de modo igual, na população dos enunciados efetivos, apresentam-se sob a forma de "ou bem isso... ou bem aquilo". (FOUCAULT, 2012, p. 78)
\end{abstract}

Dessa forma, termos constituidores de pares binários como prática científica/prática docente, ciência de referência/cultura da escola, antigos/novos e teoria/prática devem ser entendidos como pertencentes a um jogo de relações, ou seja, encontram-se regulados pelas mesmas condições que não necessariamente os colocam em oposição. É com base nesse debate que passamos, na próxima seção, a colocar em destaque, a partir do que foi discutido neste artigo, alguns aspectos da análise da relação entre teoria e prática na formação de professores.

\title{
4 ALGUMAS BREVES CONSIDERAÇÕES
}

Assumindo a já mencionada postura de 'vigilância epistemológica' e de 'hipercrítica' defendida por Veiga-Neto (2012), nos propusemos, nesse trabalho, a problematizar a formação inicial de professores no país, com especial destaque para as Ciências Biológicas, buscando enfrentar a dicotomia entre teoria e prática como uma aporia que, antes de ser combatida, deve ser percebida como condição de pensamento. Assim, em meio a diálogos com Michel Foucault (2003 e 2012) - e alguns de seus interlocutores no campo do Currículo (FISCHER, 2003 e 2012; POPKEWITZ, 1994, 1997 e 2001; VEIGA-NETO, 2009 e 2012) -, assim como com a história do tempo presente, vimos produzindo uma abordagem discursiva para a História e as Políticas de Currículo, focalizando a relação entre esses dois significantes. Em tal movimento, a teoria e a prática deixam de ser significadas de modo que uma se oponha a outra, em uma espécie de contradição na qual muitos estudos da área têm investido, para serem olhadas em uma perspectiva relacional, que busca entender as regularidades que proporcionam as condições de possibilidade para que essas duas noções apareçam e produzam, conjuntamente, um sistema de raciocínio que vem informando a 
formação de professores. Finalmente, defendemos que esse texto é parte importante do que nos parece uma profícua agenda de pesquisa: o investimento na construção de uma História do Currículo e das Disciplinas no (e do) tempo presente, em meio à produção de políticas, na tentativa de compreendermos como, em diferentes momentos, os discursos produzem noções de verdade sobre 'o que é' ou 'o que deve ser' o ensino e a formação de professores.

\section{REFERÊNCIAS}

ANDRADE, Everardo Paiva; FERREIRA, Marcia Serra; VILELA, Mariana Lima; AYRES et al. A dimensão prática na formação inicial docente em Ciências Biológicas e em História: modelos formativos em disputa. Ensino em Re-Vista, Uberlândia, MG, v. 12, n. 01, p. 07-

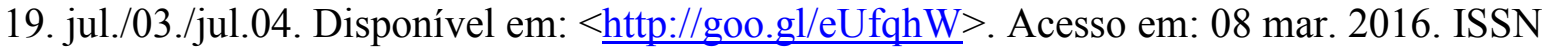
1983-1730.

AYRES, Ana Cléa Moreira. Tensão entre matrizes: um estudo a partir do curso de Ciências Biológicas da Faculdade de Formação de Professores/UERJ. 2005. 183 f. Tese (Doutorado em Educação) - Faculdade de Educação, Universidade Federal Fluminense, Niterói, RJ, 2006. Disponível em: <http://goo.gl/sKgh99>. Acesso em: 10 mar. 2016.

BOWE, Richard; BALL, Stephen J.; GOLD, Anne. Reforming education \& changing schools: case studies in policy sociology. London: Routledge, 1992.

DIAS, Rosanne Evangelista; LÓPEZ, Silvia Braña. Conhecimento, interesse e poder na produção de políticas curriculares. Currículo sem Fronteiras, Rio de Janeiro, RJ, v. 06, n.

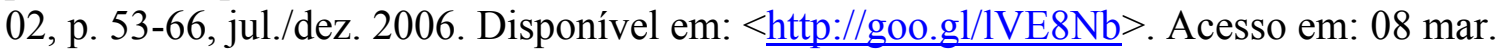
2016. ISSN 1645-1384.

FERREIRA, Marcia Serra. História do currículo e das disciplinas: apontamentos de pesquisa. In: FAVACHO, André Márcio Picanço; PACHECO, José Augusto; SALES, Shirlei Rezende (Orgs.). Currículo, conhecimento e avaliação: divergências e tensões. Curitiba: CRV, p. 75$88,2013$.

FERREIRA, Marcia Serra. História do currículo e das disciplinas: produzindo uma abordagem discursiva para investigar a formação inicial de professores nas Ciências Biológicas. In: LEITE, Miriam Soares; GABRIEL, Carmen Teresa (Orgs.). Linguagem, discurso, pesquisa e educação. Petrópolis: De Petrus: FAPERJ, 2015, p. 265-284.

FERREIRA, Marcia Serra; SOUSA, Bianca Gonçalves; CASARIEGO, Florence Mendez. História do currículo: investigando a formação inicial de professores nas Ciências Biológicas em instituições no estado do Rio de Janeiro. In: ENCONTRO NACIONAL DE PESQUISA EM EDUCAÇÃO EM CIÊNCIAS, 9., 2013, Águas de Lindóia, SP. Atas... Águas de Lindóia: ENPEC, 2013, p. 01-07. Disponível em: < http://goo.gl/sWDMP2>. Acesso em: 10 mar. 2016.

FISCHER, Rosa Maria Bueno. Foucault revoluciona a pesquisa em educação? Perspectiva, Florianópolis, SC, v. 21, n. 02, p. 371-389. jul./dez. 2003. Disponível em: $<$ https://goo.gl/Rs0nio $>$. Acesso em: 08 mar. 2016. ISSN 2175-795X. 
FISCHER, Rosa Maria Bueno. Trabalhar com Foucault: arqueologia de uma paixão. Belo Horizonte: Autêntica, 2012.

FOUCAULT, Michel. A ordem do discurso. São Paulo: Edições Loyola, 2003.

FOUCAULT, Michel. A arqueologia do saber. Rio de Janeiro: Forense Universitária, 2012.

GABRIEL, Carmen Teresa. Teoria da História, didática da História e narrativa: diálogos com Paul Ricoeur. Revista Brasileira de História, São Paulo, SP, v. 32, n. 64, p. 187-210. 2012.

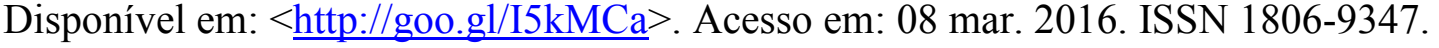

GABRIEL, Carmen Teresa. Conhecimento científico e currículo: anotações sobre uma articulação impossível e necessária. Revista Teias, Rio de Janeiro, RJ, v. 14, n. 33, p. 44-57.

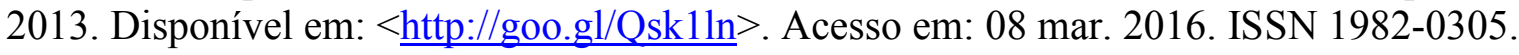

GARCIA CANCLINI, Nestor. Culturas híbridas: estratégias para entrar e sair da modernidade. São Paulo: EDUSP, 2000.

GOODSON, Ivor. A construção social do currículo. Lisboa: Educa, 1997.

HACKING, Ian. Kinds of people: moving targets. Proceedings of the British Academy. Oxford: Oxford University Press, 2007.

HALL, Stuart. A centralidade da cultura: notas sobre as revoluções culturais do nosso tempo. Educação \& Realidade, Porto Alegre, RS, v. 22, n. 02, p. 15-46. jul./dez. 1997. Disponível em: <http://goo.gl/5WL8A >. Acesso em: 10 mar. 2016. ISSN 2175-6236.

LOPES, Alice Casimiro. Política de currículo: recontextualização e hibridismo. Currículo sem Fronteiras, Rio de Janeiro, RJ, v. 05, n. 02, p. 50-64. jul./dez. 2005. Disponível em: $<$ http://goo.gl/DEOvDa $>$. Acesso em: 08 mar. 2016. ISSN 1645-1384.

POPKEWITZ, Thomas. Cosmopolitanism and the age of school reform: Science, education, and making society by making the child. New York: Routledge, 2008.

POPKEWITZ, Thomas. História do currículo, regulação social e poder. In: SILVA, Tomaz Tadeu (Org.). O sujeito da educação: estudos foucaultianos. 6. ed. Petrópolis: Vozes, 1994, p. 173-210.

POPKEWITZ, Thomas. Lutando em defesa da alma: a política do ensino e a construção do professor. Porto Alegre: Artmed, 2001.

POPKEWITZ, Thomas. Reforma educacional: uma política sociológica. Poder e conhecimento em educação. Porto Alegre: Artes Médicas, 1997.

POPKEWITZ, Thomas. Social epistemology, the reason of "reason" and the curriculum studies. Education Policy Analysis Archives, Arizona, Estados Unidos, v. 22, n. 22, p. 0123. 2014. Disponível em: < http://goo.gl/g9NevQ>. Acesso em: 08 mar. 2016. ISSN 10682341. 
SOUZA, Priscila Feitosa de; FONSECA, Liliane Ramos da; ETTER, Fernanda et al. Prática como componente curricular: entre tradições e novidades no currículo da formação de professores nas Ciências Biológicas. In: ENCONTRO NACIONAL DE PESQUISA EM EDUCAÇÃO EM CIÊNCIAS, 10., 2015, Águas de Lindóia, SP. Atas... Águas de Lindóia: ENPEC, 2015, p. 01-08. Disponível em: <http://goo.gl/bBnGjS > . Acesso em: 10 mar. 2016.

TERRERI, Letícia. Políticas curriculares para a formação de professores em Ciências Biológicas: investigando sentidos de prática. 2008. 198 f. Dissertação (Mestrado em Educação) - Faculdade de Educação, Universidade Federal do Rio de Janeiro, Rio de Janeiro,

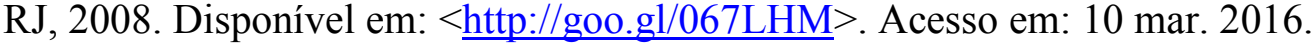

TERRERI, Letícia; FERREIRA, Marcia Serra. Políticas curriculares para a formação de professores: sentidos de teoria e prática nas Ciências Biológicas. Revista de Educação Pública, Cuiabá, MT, v. 22, n. 51, p. 999-1020. set./dez. 2013. Disponível em: < http://goo.gl/3hc7Ve>. Acesso em: 08 mar. 2016. ISSN 2238-2097.

VEIGA-NETO, Alfredo. Teoria e método em Michel Foucault (im)possibilidades. Cadernos de Educação, Pelotas, RS, n. 34, p. 83-94. set./dez. 2009. Disponível em:

$<$ https://goo.gl/rzJ4v4>. Acesso em: 08 mar. 2016. ISSN 2178-079X.

VEIGA-NETO, Alfredo. É preciso ir aos porões. Revista Brasileira de Educação, Rio de Janeiro, RJ, v.17, n. 50, p. 267-282. mai./ago. 2012. Disponível em: <http://goo.gl/yljOeU $>$. Acesso em: 08 mar. 2016. ISSN 1809-449X.

VIANA, Gabriel Menezes; MUNFORD, Danusa; FERREIRA, Marcia Serra et al. Construindo sentidos de relações teoria-prática na formação de professores de Ciências da Natureza e Biologia. In: ENCONTRO NACIONAL DE PESQUISA EM EDUCAÇÃO EM CIÊNCIAS, 9., 2013, Águas de Lindóia, SP. Atas... Águas de Lindóia: ENPEC, 2013. p. 01-

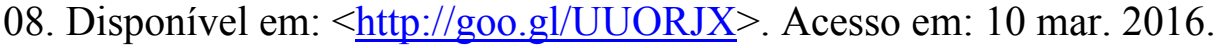

VIANA, Gabriel Menezes; MUNFORD, Danusa; FERREIRA, Marcia Serra et al. Relações entre teoria e prática na formação de professores: investigando práticas sociais em disciplina acadêmica de um curso nas Ciências Biológicas. Educação em Revista, Belo Horizonte,

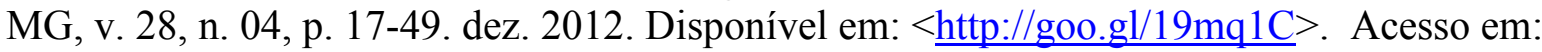
08 mar. 2016. ISSN 1982-6621.

VIANA, Gabriel Menezes; MUNFORD, Danusa; FERREIRA, Marcia Serra et al. Relações teoria-prática na formação de professores de Ciências: um estudo das interações discursivas no interior de uma disciplina acadêmica. Education Policy Analysis Archives, Arizona,

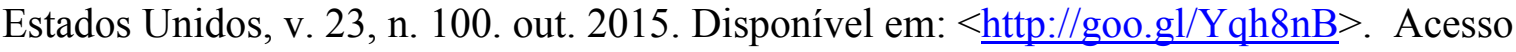
em: 08 mar. 2016. ISSN 1068-2341.

\footnotetext{
i Texto produzido no âmbito dos projetos de pesquisa 'Reformas em curso na formação de professores em Ciências Biológicas: significando a inovação curricular no tempo presente' e 'Sentidos das relações entre teoria e prática em cursos de formação de professores em Ciências Biológicas: entre Histórias e Políticas de Currículo', ambos coordenados pela primeira autora e desenvolvidos com recursos do CNPq e da FAPERJ.

ii Garcia Canclini, em seus estudos sobre a cultura urbana, mostra como os monumentos urbanos, por exemplo, perderam o seu caráter legitimador do que é tradicional. Esses ao tornarem-se parte da trama urbana, constroem interseções entre o moderno e o pós-moderno. Haveria para Canclini três processos que contribuem para esse fenômeno: o descolecionamento, a desterritorialização e a produção de gêneros impuros. O descolecionamento
} 
está relacionado ao entrecruzamento entre o culto e o popular. Para o autor, "as culturas já não se agrupam em grupos fixos e estáveis e portanto desaparece a possibilidade de se ser culto conhecendo o repertório das 'grandes obras', ou ser popular porque se domina o sentido dos objetos e mensagens produzidos por uma comunidade mais ou menos fechada" (GARCIA CANCLINI, 2000, p. 304). As descoleções, para o autor, "são capazes de romper as hierarquias, ainda que não sejam capazes de dissolver as diferenças entre classes" (LOPES, 2005, p. 57). A desterritorialização envolve a perda de uma relação natural entre cultura e território geográfico e social e traz consigo um outro processo associado que seria o reterritorialização, onde as produções simbólicas assumiriam novos espaços territoriais. A produção de gêneros impuros, por fim, seria o resultado do descolecionamento e da desterritorialização e reterritorialização, que constituem (ou constituiriam) gêneros híbridos.

iii BRASIL. Parecer CNE/CP 9/2001. Estabelece as Diretrizes Curriculares Nacionais para a Formação de Professores da Educação Básica, em nível superior, curso de licenciatura, de graduação plena. Disponível em: $<$ http://goo.gl/Qeoqx0>.

iv BRASIL. Parecer CNE/CP 28/2001. Dá nova redação ao Parecer CNE/CP 21/2001 e discorre sobre a duração e a carga horária dos cursos de Formação de Professores da Educação Básica, em nível superior, curso de licenciatura, de graduação plena. Disponível em: $<$ http://goo.gl/tZrcgq $>$.

v BRASIL. Resolução CNE/CP 1/2002. Institui as Diretrizes Curriculares Nacionais para a Formação de Professores da Educação Básica, em nível superior, curso de licenciatura, de graduação plena. Documento disponível em: <http://goo.gl/29DkIs $>$.

vi BRASIL. Resolução CNE/CP 2/2002. Institui a duração e a carga horária dos cursos de Formação de

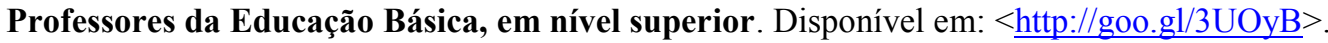

vii BRASIL. Resolução CNE/CP 2/2015. Define as Diretrizes Curriculares Nacionais para a formação inicial em nível superior (cursos de licenciatura, cursos de formação pedagógica para graduados e cursos de segunda licenciatura) e para a formação continuada. Disponível em: <http://goo.gl/XnX1SG $>$.

viii A autora refere-se especialmente à trilogia 'Temps et Récit', publicada entre 1983/85.

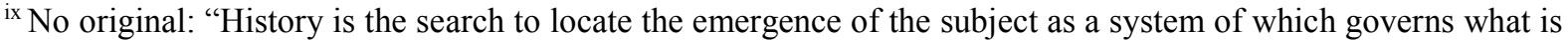
possible to say, think, and do. The problematizing of what is taken as natural and outside of "time" is to make fragile the causality of the present and the possibilities of alternatives that are outside of the existing inscriptions of the past that govern the future. Its strategy to think about change is different from those embodied in historicism. Agency is in depriving the self of the reassuring stability of life and to challenge the assumption that liberty and freedom are dependent on the calculation and administration of the human subject. Where paradoxically historicism organizes the past to speak about the future, historicizing is a critical project to make fragile the seeming causality of the presente" (POPKEWITZ, 2014, p. 12).

x Embora os autores destaquem a importância desse contexto como sendo o responsável pelo processo de iniciação da formulação das políticas, compreendemos que a própria noção de ciclo rompe tanto com a noção de verticalidade como com a ideia de uma suposta origem ou de começo. Assim, mesmo que o modelo preveja a participação de diferentes contextos e modos distintos de endereçamento desses textos, a ideia de circulação de discursos e sujeitos permite, ainda que se reconheça a assimetria nas relações de poder envolvidas no processo de formulação das políticas, que rompamos com a verticalização tão usual nos modelos top-down ou bottom-up. ${ }^{x i} \mathrm{Na}$ citação, a autora faz menção à $7^{\mathrm{a}}$ edição brasileira da obra 'A Arqueologia do saber'.

xii No original: "Sometimes we study a kind of person just to admire, to understand, to encourage and perhaps even to emulate, as (sometimes) with genius. We think of these kinds of people as given, as definite classes defined by definite properties. As we get to know more about these properties, we will be able to control, to help, to change, or to emulate them better. But it is not quite like that. They are moving targets because our investigations interact with the targets themselves, and change them. And since they are changed, they are not quite the same kind of people as before. The target has moved. That is the looping effect. Sometimes our sciences create kinds of people that in a certain sense did not exist before. That is making up people" (HACKING, 2007, p. 293).

xiii BRASIL. Parecer CNE/CP 9/2001. Estabelece as Diretrizes Curriculares Nacionais para a Formação de Professores da Educação Básica, em nível superior, curso de licenciatura, de graduação plena. Documento disponível em: < http://goo.gl/Qeoqx0>.

xiv BRASIL. Parecer CNE/CP 28/2001. Dá nova redação ao Parecer CNE/CP 21/2001 e discorre sobre a duração e a carga horária dos cursos de Formação de Professores da Educação Básica, em nível superior, curso de licenciatura, de graduação plena. Disponível em: $<\underline{\mathrm{http}}: / / \mathrm{goo} . \mathrm{gl} / \mathrm{tZrcgq}>$.

xv BRASIL. Parecer CNE/CP 2/2015. Diretrizes Curriculares Nacionais para a Formação Inicial e

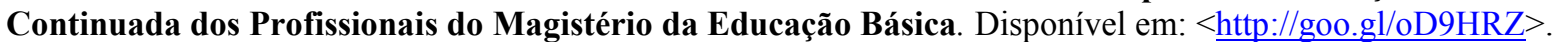

\begin{tabular}{l|l|l|l|l|l|l|} 
(C) ETD -Educ. temat. digit. & Campinas, SP & v.18 & n. 2 & p.495-510 & abr./jun.2016 & ISSN 1676-2592
\end{tabular}


xvi BRASIL. Resolução CNE/CP 1/2002. Institui as Diretrizes Curriculares Nacionais para a Formação de Professores da Educação Básica, em nível superior, curso de licenciatura, de graduação plena. Disponível em: $<$ http://goo.gl/29DkIs $>$.

xvii BRASIL. Resolução CNE/CP 2/2002. Institui a duração e a carga horária dos cursos de Formação de

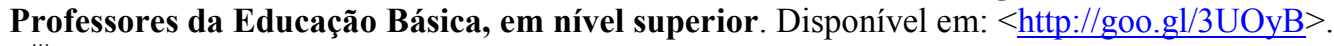

xviii BRASIL. Resolução CNE/CP 2/2015. Define as Diretrizes Curriculares Nacionais para a formação inicial em nível superior (cursos de licenciatura, cursos de formação pedagógica para graduados e cursos

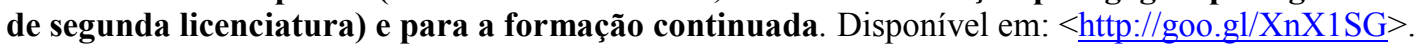

\section{Como citar este documento:}

FERREIRA, Marcia Serra; DOS SANTOS, Andre Vitor Fernandes; TERRERI, Leticia. Currículo da formação de professores nas Ciências Biológicas: por uma abordagem discursiva para investigar a relação entre teoria e prática. ETD - Educação Temática Digital, Campinas, SP, v. 18, n. 2, jul. 2016. ISSN 1676-2592. Disponível em: 〈http://periodicos.sbu.unicamp.br/ojs/index.php/etd/article/view/8644089>. Acesso em: 05 jul. 2016. doi:http://dx.doi.org/10.20396/etd.v18i2.8644089. 